\title{
Deficient NRG1-ERBB signaling alters social approach: relevance to genetic mouse models of schizophrenia
}

\author{
Sheryl S. Moy • H. Troy Ghashghaei • Randal J. Nonneman • Jill M. Weimer • \\ Yukako Yokota • Daekee Lee • Cary Lai - David W. Threadgill • E. S. Anton
}

Received: 15 February 2009 / Accepted: 5 May 2009 /Published online: 27 May 2009

(C) Springer Science + Business Media, LLC 2009

\begin{abstract}
Growth factor Neuregulin 1 (NRG1) plays an essential role in development and organization of the cerebral cortex. NRG1 and its receptors, ERBB3 and ERBB4, have been implicated in genetic susceptibility for schizophrenia. Disease symptoms include asociality and altered social interaction. To investigate the role of NRG1ERBB signaling in social behavior, mice heterozygous for an $\mathrm{Nrg} 1$ null allele $(\mathrm{Nrg} \mathrm{I}+-$ ), and mice with conditional ablation of Erbb3 or Erbb4 in the central nervous system, were evaluated for sociability and social novelty preference in a three-chambered choice task. Results showed that deficiencies in NRG1 or ERBB3 significantly enhanced sociability. All of the mutant groups demonstrated a lack of social novelty preference, in contrast to their respective wild-type controls. Effects of NRG1, ERBB3, or ERBB4 deficiency on social behavior could not be attributed to general changes in anxiety-like behavior, activity, or loss of
\end{abstract}

S. S. Moy $(\varangle) \cdot$ R. J. Nonneman $\cdot$ E. S. Anton $(\bowtie)$

Carolina Center for Developmental Disabilities, CB\#7146,

University of North Carolina School of Medicine,

Chapel Hill, NC 27599, USA

e-mail: ssmoy@med.unc.edu

S. S. Moy

Department of Psychiatry,

University of North Carolina School of Medicine,

Chapel Hill, NC, USA

H. Troy Ghashghaei · J. M. Weimer · Y. Yokota • E. S. Anton $(\bowtie)$

UNC Neuroscience Research Center, CB\#7250,

University of North Carolina School of Medicine,

Chapel Hill, NC 27599, USA

e-mail: eva_anton@med.unc.edu

H. Troy Ghashghaei

Department of Molecular Biomedical Science,

North Carolina State University,

Raleigh, NC, USA olfactory ability. $\mathrm{Nrg} 1+/-$ pups did not exhibit changes in isolation-induced ultrasonic vocalizations, a measure of emotional reactivity. Overall, these findings provide evidence that social behavior is mediated by NRG1-ERBB signaling.

Keywords Grin1 - Growth factor - NMDA receptor . Schizophrenia $\cdot$ Sociability $\cdot$ Social novelty

\section{Introduction}

Genome-wide linkage studies, case-control association studies, and functional data have implicated Neuregulin 1 (NRG1) in the etiology of schizophrenia [18, 56, 57]. NRG1 is known to play critical roles in the development and patterning of the cerebral cortex $[1,2,13,15,35,51$,

\section{Lee}

Division of Life and Pharmaceutical Sciences,

Ewha Womans University,

Seoul, Korea

C. Lai

Department of Psychological and Brain Sciences and Program in Neuroscience, Indiana University, Bloomington, IN, USA 
55]. NRG1 promotes the generation and maintenance of cerebral cortical radial glia, and enhances the migration of cortical neuroblasts in the embryonic cortex. NRG1-ERBB4 receptor tyrosine kinase interactions also promote neural progenitor cell proliferation and interneuronal migration in the adult forebrain. NRG1 can induce the expression of $N$ methyl-D-aspartate receptor (NMDAR) $2 \mathrm{C}$ and GABA-A $\beta 2$ subunits in cerebellar granule neurons, and the $\alpha-7$ subunit of acetylcholine receptor (AchR) in hippocampal neurons [5]. In the hippocampal CA1 region, NRG1 can reverse or rapidly suppress the induction of long term potentiation (LTP) [22, 28], possibly through stimulation of dopamine release and subsequent D4 dopamine receptor signaling [29]. Moreover, NRG1-ERBB4 interactions can both modulate glutamate receptor activity in hippocampus and enhance GABAergic release from interneurons in the prefrontal cortex [32, 59]. Finally, NRG1-ERBB4 signaling can modulate gamma oscillations in cortex, thought to be critical for normal cognitive functions [11, 12].

Collectively, these studies suggest that defects in NRG1ERBB signaling could alter the generation, placement, differentiation, or physiological function of neurons in the developing and adult brain. Resultant changes in neural circuitry and electrophysiology in the cerebral cortex may thus lead to neurodevelopmental disorders such as schizophrenia. In support of this hypothesis, recent studies indicate that altered NRG1-ERBB4 interactions may enhance susceptibility to schizophrenia [45] and that NRG1(I) expression is deregulated in dorsolateral prefrontal cortex and hippocampus in schizophrenia [19, 31]. We investigated whether NRG1- and ERBB- deficient mouse models have alterations in social approach, relevant to symptoms of asociality and impaired social interaction in schizophrenia, as well as autism, fragile $\mathrm{X}$ syndrome, and other neurodevelopmental disorders.

Mice homozygous for a targeted null allele of $\mathrm{Nrgl}$ (Nrgl-l-) die during embryogenesis, but heterozygous mice $(\mathrm{Nrgl}+\mathrm{l})$ are viable [36]. $\mathrm{Nrgl} / \mathrm{l}-$ mice have significant decreases in $\mathrm{Nrg} 1 \mathrm{mRNA}$ expression as embryos and adults, suggesting that heterozygous carriers can be used to study disruption of NRG1-ERBB signaling postnatally. In particular, $\mathrm{Nrg} 1+/-$ mice have been examined as a possible mouse model relevant to genetic susceptibility for schizophrenia. Several studies have found that $\mathrm{Nrg} 1 \mathrm{mice}$ are hyperactive in various experimental settings $[4,14,46$, 47, 57]. However, there are conflicting results from acoustic startle tests of sensorimotor gating, with reports of impaired prepulse inhibition [57] and normal prepulse inhibition [4] in Nrg $1+/-$ mice. Similarly, both reduced [4] and unchanged [47] anxiety-like behavior have been observed. One study failed to find any behavioral alterations in $\mathrm{Nrg} 1$ $+/-$ mice during a social interaction test [4], while others have reported increased aggression [46, 47]. The particular background strains used to maintain different $\mathrm{Nrg} 1$ mutant lines may be a factor in the inconsistent behavioral profiles.

An additional source for inconsistencies in phenotypes may be due to differences in how and which isoform of $\mathrm{Nrgl}$ was disrupted. $\mathrm{Nrgl}$ mutant lines include those targeting the transmembrane (TM) domain $[4,46,47,57]$ and the immunoglobulin (Ig)-like domain [50]. The $\mathrm{Nrg} 1$ mutant line in the present study had targeted deletion of the epidermal growth factor (EGF)-like domain that is common to all isoforms $[14,36]$. It is notable that, unlike other $\mathrm{Nrg} 1$ mutant lines, the Ig-domain $\mathrm{Nrgl} / \mathrm{l}-$ mice do not show hyperactivity [50].

In the present study, social approach behaviors were examined in two separate cohort groups of $\mathrm{Nrgl}+/-$ mice using a three-chambered choice test $[39,44]$. The cohorts were assessed for sociability, defined as a preference for spending more time in the proximity of another mouse, versus being alone, and for social novelty preference, defined as preference for a novel social partner, versus an already-investigated social partner. Furthermore, mice with central nervous system (CNS) deletion of Erbb3 or Erbb4 were evaluated using the same test. In contrast to $\mathrm{Nrgl+/}$ mice, Erbb3+/- mice are not hyperactive in an open field test [14]. However, Erbb4+/- mice have a mild increase in locomotion, although there are no detectable changes in prepulse inhibition of acoustic startle responses [57]. The present study included Erbb3 and Erbb4 conditional mutant lines in order to determine if changes in social behavior observed in $\mathrm{Nrgl}+/-$ mice were mediated through specific ERBB receptors.

An important issue for interpreting results from social approach tests is that altered preference for the social partner may reflect general changes in activity, motor or sensory function, or anxiety, rather than selective effects on social behavior. In the present study, information from several control measures, including activity in an open field and anxiety-like behavior in an elevated plus maze, was considered in the interpretation of results from the social choice test. These measures provided evidence for whether changes in social approach could be attributed to overall hyperactivity, altered anxiety, or other characteristics of the mutant mice.

\section{Methods}

Animals

Nrgl null mutation Wild-type (Nrgl+/+) and heterozygous (Nrg1+/-) male mice were maintained on a B6D2F1/CrlBR (or BDF1; Charles River) background. Two separate cohorts of adult $\mathrm{Nrgl}+/+$ and $+/-$ mice were evaluated. Mice in cohort 1 were 1.5 to 3 months of age (mean age $=$ 
2.7 months) at the beginning of testing, while mice in cohort 2 were 2 to 5.5 months of age (mean age= 4.2 months) at the beginning of testing. In addition, a separate set of $\mathrm{Nrgl}+/+$ and $+/-$ mice was tested for ultrasonic vocalizations during the neonatal period. Female $\mathrm{Nrgl} /++$ mice were crossed with male $\mathrm{Nrgl+/}-$ mice to provide litters. Day of birth was considered postnatal day (PD) 1. Pups from 7-10 L were tested on PDs 5, 7, and 10.

Erbb3 conditional deletion Male mice with a conditional deletion of $E r b b 3$ ( $E r b b 3^{\text {tm2Dwt }}$, Lee et al. submitted) were crossed with mice carrying Nestin-Cre recombinase to generate a CNS-specific deletion of Erbb3 (Erbb3 $3^{t m 2 D w t / t m 2 D w t}$, Nestin-Cre). Mice were on a mixed C57BL/6J $\times 129$ S1/SvImJ background. Testing began when animals were 3 to 6 months of age (mean age was 4.6 months).

Erbb4 conditional deletion Mice in which the second exon of the Erbb4 gene was flanked by loxP were crossed with transgenic mice that expressed $C r e$ recombinase under the control of human GFAP ( $h G F A P)$ promoter to generate mice with conditional deletion of Erbb4 in the CNS (Erbb4 $4^{\text {lox/- } h G F A P-C r e ~[1]) . ~ M i c e ~ w e r e ~ o n ~ a ~ m i x e d ~}$ C57BL/6J $\times 129 \mathrm{~S} 1 / \mathrm{SvImJ}$ background. Testing began when mice were approximately 8 months of age.

Subject numbers for each of the adult mouse lines are given in Table 1. Mice were housed in ventilated cages, with free access to water and Purina 5,058 chow. The housing room had a 12-hr light/dark cycle (lights off at 7:00 P.M.). Genotyping was conducted by PCR from tail or toe tissue samples. All procedures were conducted in strict compliance with the policies on animal welfare of the National Institutes of Health and the University of North Carolina (stated in the "Guide for the Care and Use of Laboratory Animals," Institute of Laboratory Animal Resources, National Research Council, 1996 edition).

\section{Behavioral testing}

The order of testing for each adult group was: 1) elevated plus maze; 2) neurobehavioral screen; 3 ) activity in an open field; 4) rotarod; 5) social approach test; and 6) buried food test for olfactory ability. Only one procedure was conducted per day. Detailed descriptions of these tests have been previously published [42]. For the neonatal assessments, pups were tested for ultrasonic vocalizations on postnatal days 5,7 , and 10 .

Elevated plus-maze test Mice were given one 5-min trial on the plus-maze, which had two closed arms, with walls $20 \mathrm{~cm}$ in height, and two open arms. The maze was elevated $50 \mathrm{~cm}$ from the floor, and the arms were $30 \mathrm{~cm}$ long. Animals were placed on the center section $(8 \mathrm{~cm} \times$ $8 \mathrm{~cm}$ ), and allowed to freely explore the maze. Arm entries were defined as all four paws entering an arm. Entries and time in each arm were recorded during the trial by a human
Table 1 Control measures in Nrg1, Erbb3, and Erbb4 mouse lines. Data shown are means \pm SEM for body weight, percent time in and percent entries into the open arms of an elevated plus maze, total arm entries on the maze, latency to fall from a rotarod (trial 5), latency to find buried food and percent of group finding the food in a test for olfactory ability

\begin{tabular}{|c|c|c|c|c|c|c|c|c|c|}
\hline & \multirow[t]{2}{*}{$\mathrm{N}$} & \multirow[t]{2}{*}{ Body weight (g) } & \multicolumn{2}{|c|}{ \%Open arm } & \multirow{2}{*}{$\begin{array}{l}\text { Total entries } \\
\text { Entries }\end{array}$} & \multicolumn{2}{|c|}{ Rotarod latency (s) } & \multicolumn{2}{|c|}{ Olfactory test } \\
\hline & & & Time & Entries & & Trial 1 & Trial 5 & latency (s) & $\%$ group \\
\hline \multicolumn{10}{|l|}{ Nrg1 } \\
\hline \multicolumn{10}{|l|}{ Cohort 1} \\
\hline $\mathrm{Nrgl}^{+/+}$ & 10 & $27 \pm 1$ & $4 \pm 1 \%$ & $11 \pm 2 \%$ & $16 \pm 1$ & $141 \pm 25$ & $260 \pm 21$ & $396 \pm 120$ & $70 \%$ \\
\hline $\mathrm{Nrgl}^{+/-}$ & 10 & $27 \pm 1$ & $6 \pm 2 \%$ & $15 \pm 3 \%$ & $19 \pm 2$ & $103 \pm 30$ & $230 \pm 28$ & $205 \pm 89$ & $90 \%$ \\
\hline \multicolumn{10}{|l|}{ Cohort 2} \\
\hline $\mathrm{Nrgl}^{+/+}$ & 16 & $35 \pm 1$ & $4 \pm 1 \%$ & $9 \pm 2 \%$ & $12 \pm 1$ & $236 \pm 17$ & $300 \pm 0$ & $316 \pm 90$ & $75 \%$ \\
\hline $\mathrm{Nrgl}^{+/-}$ & 15 & $33 \pm 1$ & $4 \pm 1 \%$ & $11 \pm 3 \%$ & $12 \pm 2$ & $207 \pm 22$ & $295 \pm 3$ & $75 \pm 12 *$ & $100 \%$ \\
\hline Erbb3 WT & 10 & $33 \pm 2$ & $2 \pm 1 \%$ & $11 \pm 6 \%$ & $5 \pm 2$ & $77 \pm 11$ & $169 \pm 17$ & $144 \pm 85$ & $90 \%$ \\
\hline Erbb3 cKO & 12 & $25 \pm 0$ * & $0.5 \pm 0 \%$ & $4 \pm 2 \%$ & $6 \pm 1$ & $132 \pm 14^{*}$ & $187 \pm 21$ & $158 \pm 32$ & $100 \%$ \\
\hline Erbb4 WT & $11^{\mathrm{a}}$ & $34 \pm 4^{\mathrm{c}}$ & $22 \pm 4 \%$ & $25 \pm 4 \%$ & $25 \pm 3$ & $110 \pm 30$ & $240 \pm 32$ & $172 \pm 77$ & $90 \%$ \\
\hline Erbb4 cKO & $14^{\mathrm{b}}$ & $43 \pm 1 * \mathrm{c}$ & $30 \pm 3 \%$ & $29 \pm 2 \%$ & $31 \pm 2$ & $61 \pm 13$ & $234 \pm 24$ & $474 \pm 104 *$ & $57 \%$ \\
\hline
\end{tabular}

WT wild-type, $c K O$ conditional knockout

a 3 males and 8 females

${ }^{b} 7$ males and 7 females. All other subject numbers are for male mice

${ }^{\mathrm{c}}$ Body weights are given for male mice

${ }^{*} p<0.05$, comparison to wild-type group from same mouse line 
observer via computer coding. Percent open arm time was calculated as $100 \times$ (time spent on the open arms/(time in the open arms + time in the closed arms)). Percent open arm entries was calculated using the same formula.

Neurobehavioral screen Mice were evaluated for general health, including body weight, appearance of fur and whiskers, body posture, and normality of gait. Reflexive reactions were assessed with a gentle touch from a cotton swab to the whiskers on each side of the face, an approach of the cotton swab to the eyes, and the sound from a metal clicker. Animals were also observed for the visual placing reflex (forepaw extension when lowered toward a visible surface), and for ability to grasp a metal grid with forepaws and hindpaws.

Open field Exploratory activity in a novel environment was assessed for $1 \mathrm{~h}$ in a photocell-equipped automated open field $(40 \mathrm{~cm} \times 40 \mathrm{~cm} \times 30 \mathrm{~cm}$; Versamax system, Accuscan Instruments). Measures were taken of total distance traveled during the test. Activity chambers were contained inside soundattenuating boxes, equipped with houselights and fans.

Rotarod performance Mice were assessed for balance and motor coordination on an accelerating rotarod (Ugo-Basile, Stoelting Co., Wood Dale, Il). Revolutions per minute (rpm) were set at an initial value of 3 , with a progressive increase to a maximum of $30 \mathrm{rpm}$ across the 5-min test session. Each animal was given a test session consisting of three trials, with $45 \mathrm{~s}$ between each trial. Two additional trials were given $48 \mathrm{~h}$ later. Latency to fall, or to rotate off the top of the turning barrel, was measured by the rotarod timer.

Olfactory test following food deprivation Several days before the olfactory test, an unfamiliar food (Froot Loops, Kellogg Co., Battle Creek, MI) was placed overnight in the home cages, in order to avoid food neophobia on the day of testing. 16-20 h before the test, all food was removed from the home cage. On the day of the test, each mouse was placed in a large, clean tub cage $(46 \mathrm{~cm} \mathrm{~L} \times 23.5 \mathrm{~cm} \mathrm{~W} \times$ $20 \mathrm{~cm} \mathrm{H}$ ), containing $3 \mathrm{~cm}$ deep paper chip bedding (Canbrands Product, Moncton NB, Canada), and allowed to explore for $5 \mathrm{~min}$. The animal was removed from the cage, and 1 Froot Loop was buried in the cage bedding, approximately $1 \mathrm{~cm}$ below the surface of the litter. The subject mouse was then returned to the cage for a $15 \mathrm{~min}$ test. Measures were taken of latency to find the buried food.

Sociability and preference for social novelty Mutant lines were tested in an automated three-chambered box [39, 42, 44]. Dividing walls had retractable doorways allowing access into each chamber. The automated box had photocells embedded in each doorway to allow quantification of entries and duration in each chamber of the social test box.
The chambers of the apparatus were cleaned with water and dried with paper towels between each trial. At the end of each test day, the apparatus was sprayed with $70 \%$ ethanol and wiped clean with paper towels.

The choice test had three 10-min phases: 1) Habituation. The test mouse was first placed in the middle chamber and allowed to explore, with the doorways into the two side chambers open. 2) Sociability. After the habituation period, the test mouse was enclosed in the center compartment of the social test box, and an unfamiliar mouse (stranger 1; an adult $\mathrm{C} 57 \mathrm{BL} / 6 \mathrm{~J}$ male) was enclosed in a wire cage $(11 \mathrm{~cm}$ H, 10.5 bottom diameter, Galaxy Cup, Spectrum Diversified Designs, Inc., Streetsboro, Ohio) and placed in a side chamber. The location for stranger 1 alternated between the left and right sides of the social test box across subjects. An empty wire cage was placed in the opposite side chamber, to serve as a novel object control. Following placement of stranger 1, the doors were re-opened, and the subject was allowed to explore the entire social test box. Measures were taken of the amount of time spent in each chamber and the number of entries into each chamber by the automated testing system. 3) Preference for social novelty. At the end of the sociability test, each mouse was further tested for preference to spend time with a new stranger. A new unfamiliar mouse was placed in the wire cage that had been empty during the previous session. The test mouse then had a choice between the first, already-investigated mouse (stranger 1) and the novel unfamiliar mouse (stranger 2). The same measures were taken as with the sociability test.

Ultrasonic vocalizations On PDs 5, 7, and 10, the home cage containing the dam and litter was taken into the laboratory. The dam was removed, and the home cage was kept warm by placement on a heated surface $\left(32.5^{\circ} \mathrm{C}\right.$, hotplate apparatus, IITC Life Science, Woodland Hills, CA). For the test, each pup was taken from the home cage and placed into a plastic beaker. The beaker was set into a sound-attenuating chamber (a small cooler), and ultrasonic vocalizations were recorded for $5 \mathrm{~min}$ by a bat detector and Ultravox software (Noldus Information Technology, Wageningen, the Netherlands). Measures included vocalization frequency and average duration in the $50 \mathrm{kHz}$ range. Data were also recorded at the 30,40 , and $60 \mathrm{kHz}$ range from three additional bat detectors, to insure that the optimal sampling range was utilized. Following the first test on PD5, one toe was removed from each pup for genotyping and subject identification.

Statistical analysis

Data from each mutant mouse line were analyzed using 1way ANOVAs (analysis of variance) or repeated measures 
ANOVAs. Significant effects of altered genotype found in the ANOVAs were further explored using post-hoc Fisher's PLSD (protected least-significant difference) tests. Social preference was determined using within-genotype repeated measures ANOVAs, with the factor of chamber side (e.g., stranger 1 side or the opposite side). For the ultrasonic vocalization experiment, $n=$ number of litters, rather than individual pups. Analyses were conducted on the mean wild-type and $\mathrm{Nrg} 1+/-$ values from each litter. Because we were not able to collect data from every litter at every time point, separate one-way ANOVAs were conducted for each postnatal day. For all comparisons, significance was set at $p<0.05$.

\section{Results}

Control measures

Mice were evaluated for general health, sensory and motor ability, anxiety-like behavior and activity, since impairment in any of these domains of function could alter performance in the three-chambered social approach test. The neurobehavioral screen did not reveal any overt deficits in the mutant mouse lines. As shown in Table 1, the $\mathrm{Nrg} 1+/+$ and $+/-$ mice of both cohort groups were similar in body weight, anxiety-like behavior on the elevated plus maze, and motor coordination on the rotarod. In cohort 2 , the Nrgl mutant mice had significantly lower latencies than wild-type mice to uncover a buried food $[F(1,28)=6.1, p=$ 0.0199].

The Erbb3 conditional mutant group weighed significantly less than the wild-type group at the beginning of testing (Table 1), and at the middle and end of testing [data not shown; post-hoc tests following significant main effect of genotype, $F(1,20)=26.05 ; p<0.0001]$. The lower body weight was not linked to differences in age (mean age \pm SEM at beginning of testing: Erbb3 wild-type, $4.7 \pm$ 0.3 months, Erbb3 mutant, $4.5 \pm 0.3$ months). In the Erbb4 groups, separate analyses for the male and female mice revealed that mutant males had significantly higher body weights than wild-type males at $8-9$ months of age $[F(1,8)=$ $8.1, p=0.0216]$. There were no differences in body weight in the female Erbb4 groups. The Erbb4 mutant mice had significantly longer latencies than the wild-type controls to uncover the buried food in the olfactory test $[F(1,23)=4.95$, $p=0.0362]$.

Previous studies have reported that $\mathrm{Nrgl}+/-$ mice have enhanced performance on the rotarod [14]. While this characteristic was not observed in either of the two $\mathrm{Nrgl}$ cohorts of the present study, the Erbb3 mutant mice had significantly longer latencies to fall than the wild-type mice
Fig. 1 Total distance traveled in a novel open field. Data shown are means $( \pm$ SEM) for each group for a one-hour test session. $\mathrm{WT}=$ wild-type, $\mathrm{cKO}=$ conditional knockout. Data were excluded from one female Erbb4 WT mouse with extremely high scores near the end of the test (i.e., $5,225 \mathrm{~cm}$ at the 55 min time point)

\section{a) Nrg1: Cohort 1}

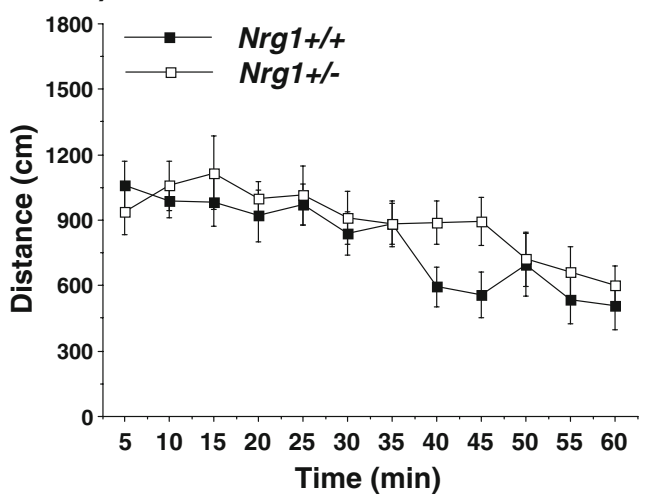

c) Erbb3

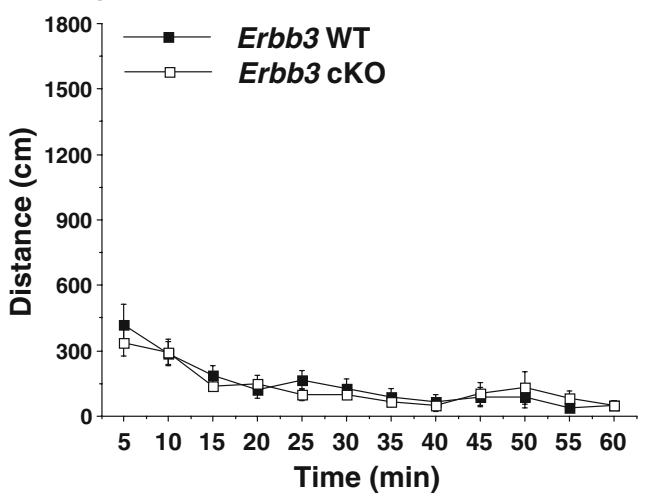

b) Nrg1: Cohort 2

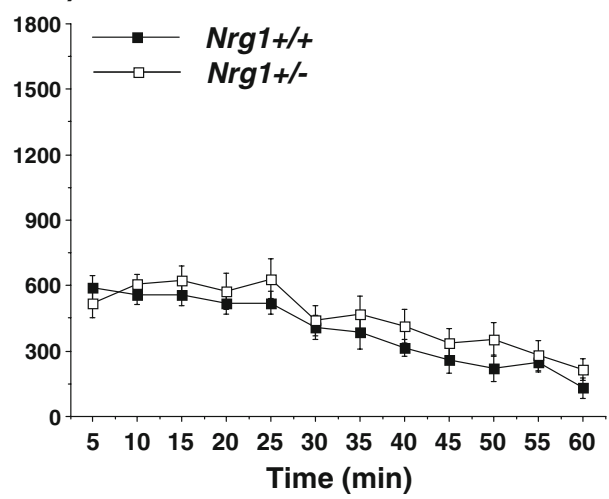

d) Erbb4

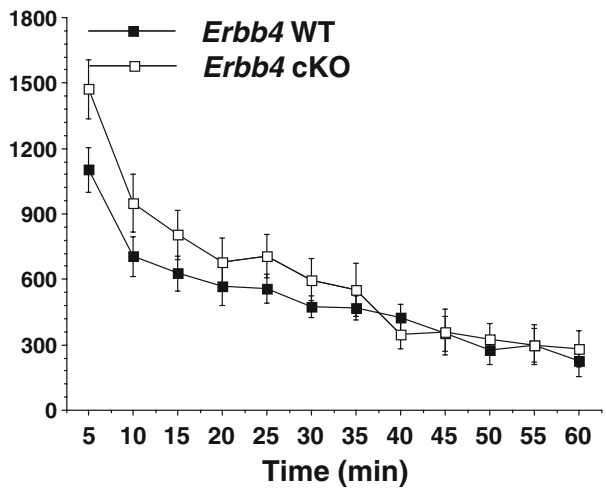


on the first day of rotarod training [post-hoc test following significant main effect of genotype, $F(1,20)=5.95, p=$ 0.0242]. As shown in Table 1, significant group differences were no longer observed by trial 5 .

Hyperactivity has been reported in $\mathrm{Nrg} 1+/-$ and Erbb4+/mice $[4,14,46,57]$. In the present study, there were no significant differences in distance traveled during a 1-hr open field test in the $\mathrm{Nrg} 1$ and $E r b b 3$ mutants (Fig. 1). A repeated measures ANOVA indicated a significant genotype $\mathrm{x}$ time interaction in the Erbb4 mice $[F(11,242)=2.44, p=0.0066]$; however, post-hoc tests failed to reveal significant group differences at any one time point.

Social approach test

Sociability Significant effects of the $\mathrm{Nrg} 1$ genotype were found in the test for sociability in both cohort groups (Fig. 2). In each set of mice, the $\mathrm{Nrgl} / \mathrm{H}$ - group spent significantly more time in the side containing the unfamiliar stranger, in comparison to the wild-type mice [post-hoc test following significant genotype $\mathrm{x}$ side interaction in cohort $1, F(1,16)=5.3, p=0.0352$, and cohort 2, $F(1,28)=5.82, p=0.0226$; and main effect of genotype in cohort $2, F(1,28)=7.6, p=0.0102]$. A similar pattern was found with the Erbb3 mutants, who spent more time in the side with the stranger mouse, and less time in the empty cage side, than the wild-type mice [posthoc tests following a significant genotype $\mathrm{x}$ side interaction $[F(1,20)=9.29, p=0.0064]$. Repeated measures ANOVAs did not indicate any significant effects of genotype in the Erbb4 groups.

Within-genotype analyses were used to determine whether the experimental groups had significant preference for the side containing the stranger mouse, versus the empty cage side, in the test for sociability. In both $\mathrm{Nrg} 1$ cohorts, the mutant mice spent significantly more time in the side with the unfamiliar stranger [cohort $1, F(1,8)=11.32, p=$ 0.0099; cohort 2, $F(1,13)=29.68, p=0.0001]$. Significant sociability was also observed in the Erbb3 mutant mice $[F$ $(1,11)=36.92, p<0.0001]$ and in the Erbb4 mutant mice $[F$ $(1,13)=14.34, p=0.0023]$. However, only one of the wildtype control groups, the $\mathrm{Nrgl} / \mathrm{H}$ mice from the second cohort, showed preference for the stranger mouse side $[F$ $(1,15)=12.69, p=0.0028]$.
Fig. 2 Time spent in each of the side chambers during the test for sociability. Data shown are mean + SEM for each group for a 10-min test. $\mathrm{WT}=$ wild-type, $\mathrm{cKO}=$ conditional knockout. $*$ $p<0.05$, within-group comparison between stranger 1 side and the empty cage side. \# $p<0.05$, comparison with corresponding wild-type group on comparable measure

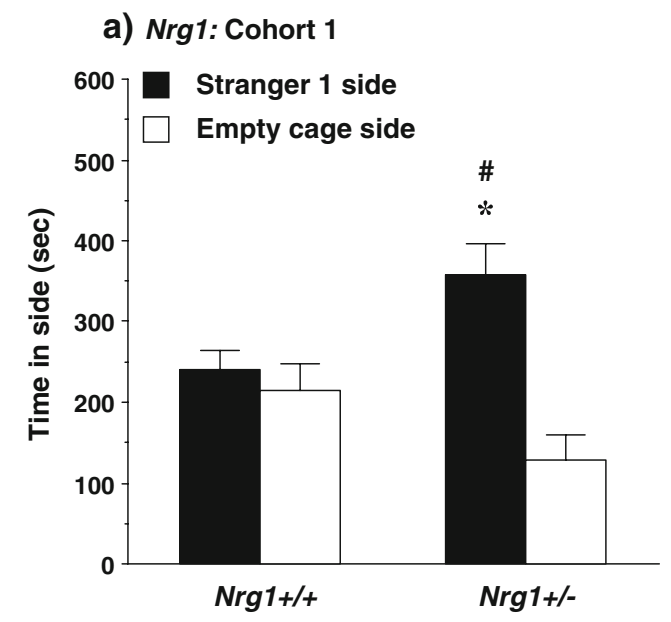

c) Erbb3

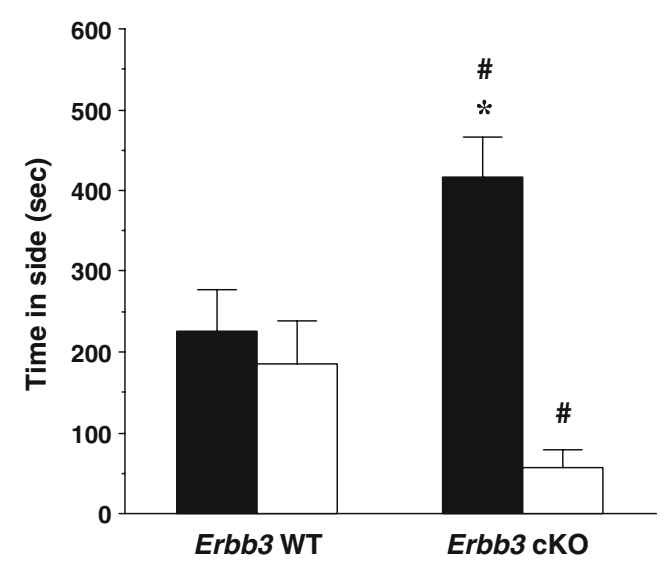

b) Nrg1: Cohort 2

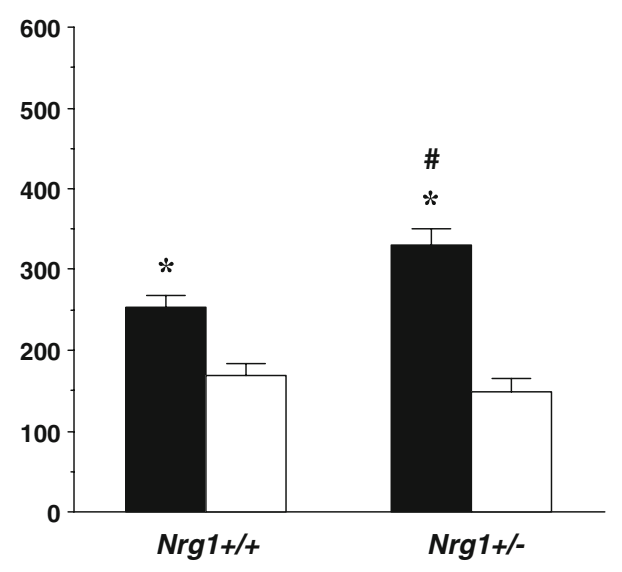

d) Erbb4

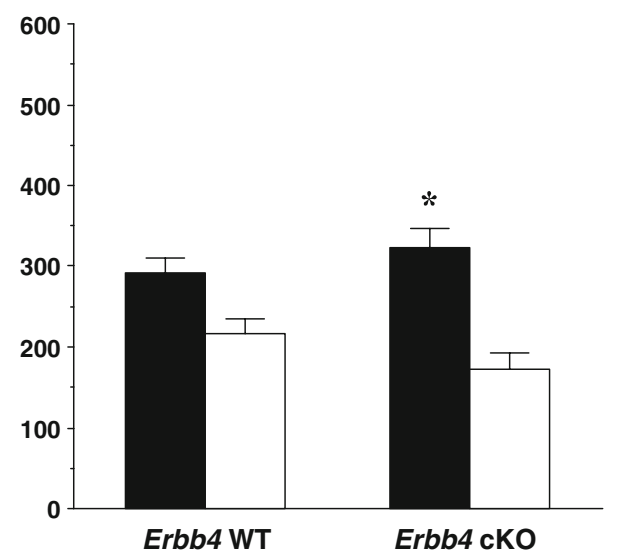


There were no differences in number of entries during the sociability test between wild-type and any of the respective mutant groups (Fig. 3).

Social novelty Repeated measures ANOVAs did not reveal any significant effects of genotype in the preference for social novelty test, although the genotype $\mathrm{x}$ side interaction approached significance in the Erbb3 group $[F(1,20)=4.24$, $p=0.0527]$. However, all of the mouse lines had the same pattern of results: none of the mutant groups demonstrated social novelty preference (Fig. 4). Only the wild-type controls had a significant preference for the newlyintroduced unfamiliar mouse (stranger 2), versus the already-investigated stranger 1. Within-genotype ANOVAs indicated that, in both cohort groups, only the $\mathrm{Nrgl+} /+$ mice had significant social novelty preference [cohort $1, F$ $(1,8)=12.45, p=0.0078$; cohort $2, F(1,15)=15.64, p=$ $0.0013]$. Significant preference for the side containing the second stranger mouse was also only observed in the Erbb3 wild-type $[F(1,9)=6.19, p=0.0346]$ and the Erbb4 wildtype $[F(1,10)=6.0, p=0.0343]$ mice. Preference for the more-novel stranger 2 mouse approached significance in the Erbb4 mutant group $[F(1,13)=3.98, p=0.0674]$.

As in the test for sociability, there were no significant effects of genotype on the measure for entries in the social novelty test (data not shown).

Ultrasonic vocalization

No differences were found in the frequency of ultrasonic vocalization by $\mathrm{Nrgl} / \mathrm{/}$ or $+/-$ mouse pups during the neonatal period (Fig. 5). Similarly, the average duration of ultrasonic cries did not differ between the groups (data not shown).

\section{Discussion}

The present study confirms that NRG1-ERBB signaling plays a role in mouse social behavior. Two separate cohort groups of male $\mathrm{Nrgl+} /-$ mice showed significantly enhanced sociability and a lack of preference for social
Fig. 3 Entries into each of the side chambers during the test for sociability. No significant differences were found between the wild-type and mutant mice in any of the mouse lines. Data shown are mean + SEM for each group for a $10-\mathrm{min}$ test. WT $=$ wild-type, $\mathrm{cKO}=$ conditional knockout

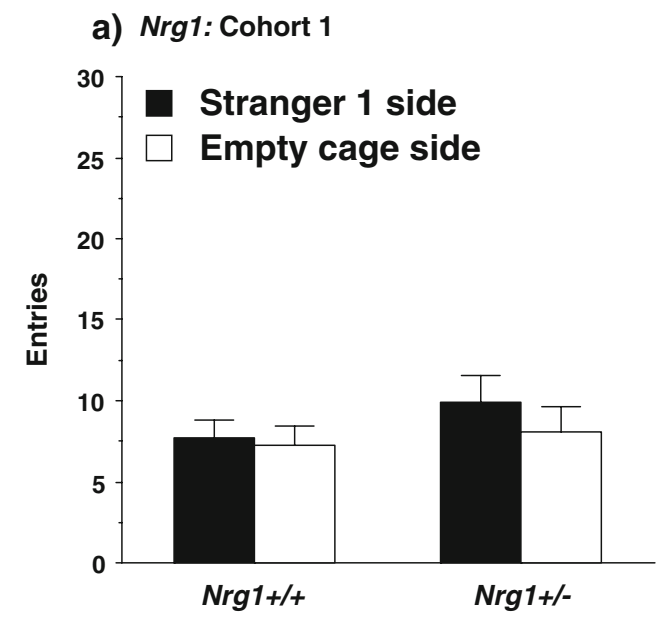

b) Nrg1: Cohort 2

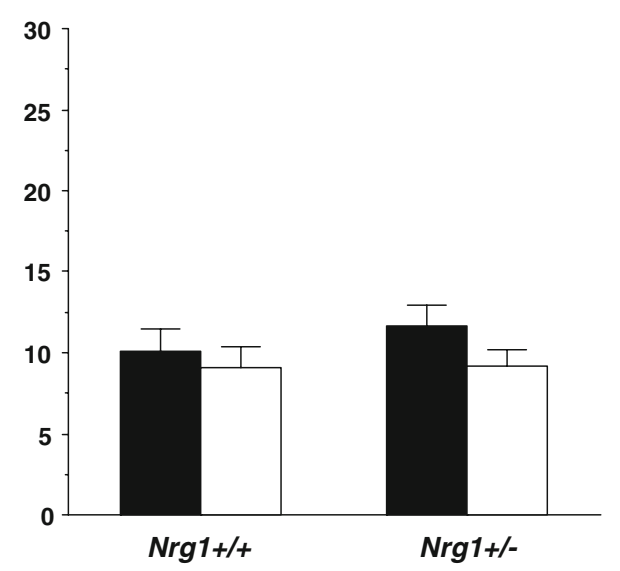

c) Erbb3

d) Erbb4

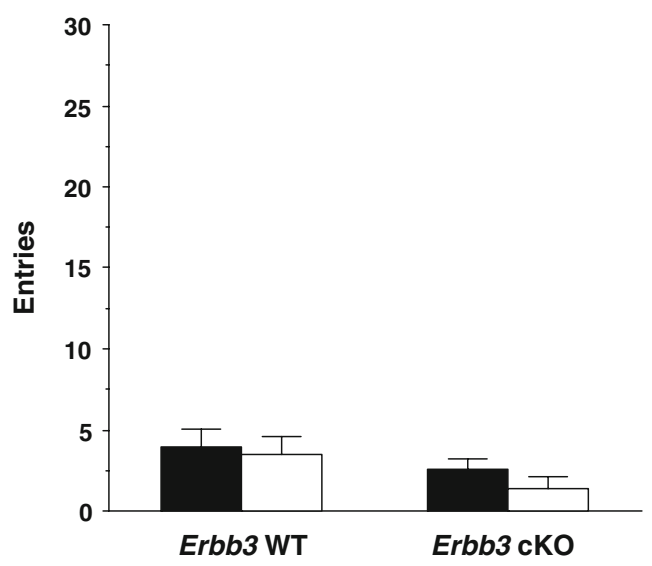

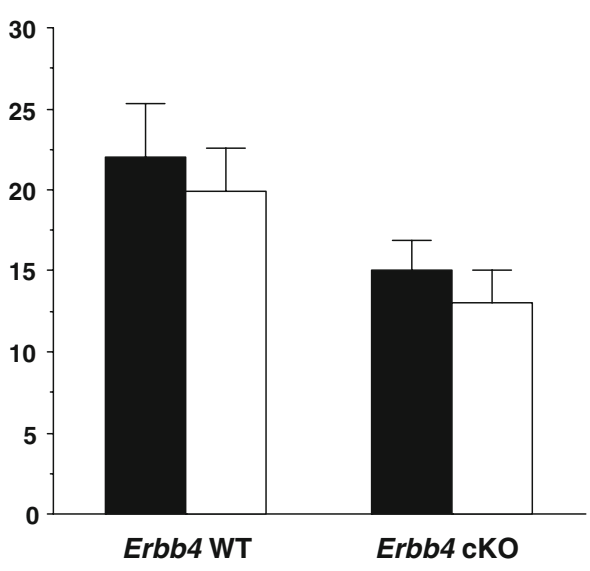


Fig. 4 Time spent in each of the side chambers during the test for social novelty preference. None of the mutant mouse lines had significant preference for spending more time in the side with the more-novel stranger 2, versus the already-investigated stranger 1. Data shown are mean + SEM for each group for a 10 -min test. $\mathrm{WT}=$ wild-type, $\mathrm{cKO}=$ conditional knockout. $* p<0.05$, within-group comparison between stranger 1 side and stranger 2 side a) Nrg1: Cohort 1

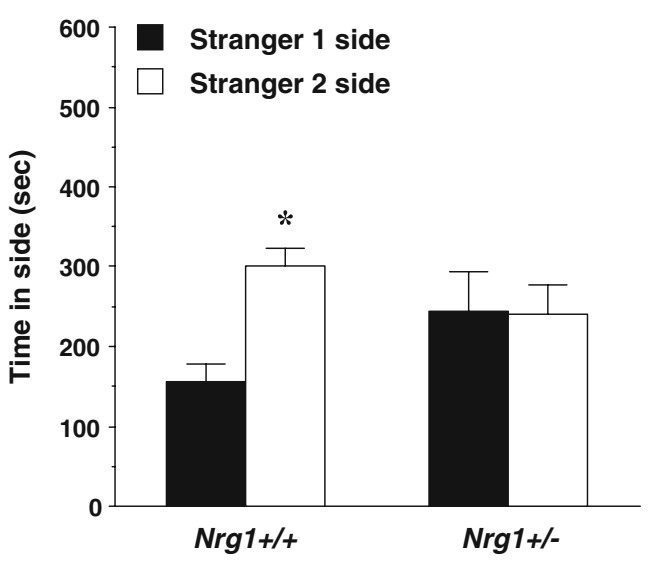

c) Erbb3

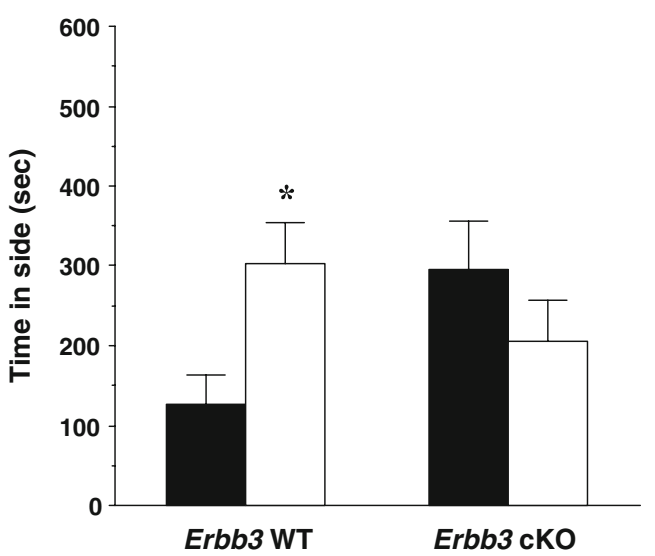

b) Nrg1: Cohort 2

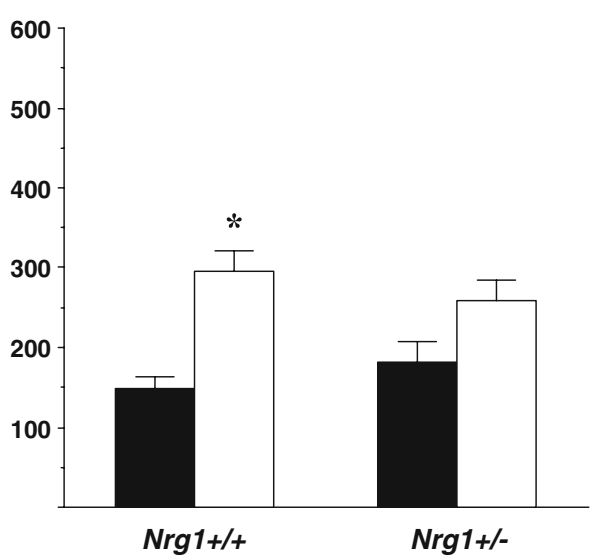

d) Erbb4

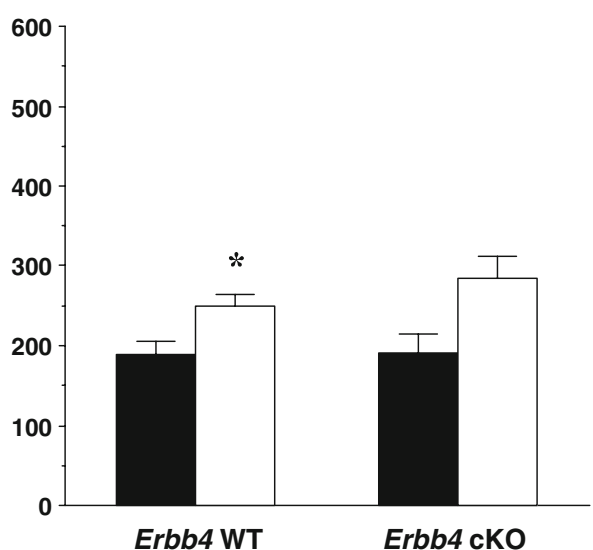

novelty in the three-chambered choice task. A strikingly similar pattern was observed in male mice with deletion of Erbb3 in the CNS. A milder phenotype was apparent in the Erbb4 mutant group, which included both males and females. The changes in social behavior could not be attributed to general hyperactivity, motor deficits, or altered anxiety-like behavior in the mutant lines.

Genetic analysis in human linkage and association studies has implicated alleles of NRG1 and ERBB4 with increased risk for schizophrenia [33, 43, 45, 57, 58], possibly through gain-of-function mutations (see review [24]). Disease pathology has been associated with an intrinsic state of NMDAR hypofunction [6, 23, 27, 37, 49]. Hahn et al. [17] have suggested that over-active NRG1-ERBB4 signaling could be an underlying mechanism for reduced function of NMDA receptors in schizophrenia. In line with this model, NRG1 activation of ERBB4 receptors was found to be significantly enhanced in postmortem tissue from the dorsolateral prefrontal cortex (PFC) of schizophrenia patients. The PFC tissue from the patients also had higher levels of ERBB4 coupling to the NR1 NMDAR subunit, thus providing a link for enhanced
NRG1 modulation of NMDAR function. Importantly, the application of NRG1 could suppress NMDAR activation in control and patient brain slices, and this effect was greater in the schizophrenia group [17]. A similar link between increased NRG1-ERBB signaling and decreased NMDAR function in PFC has been demonstrated in a rat model [16].

Disruption of normal NMDA neurotransmission can lead to deficits in social behavior, which may be relevant to social impairment and asociality observed in schizophrenia [3, 10, 53, 54]. Decreased social preference has been observed in two mouse models of intrinsic NMDA hypofunction relevant to schizophrenia. Grin $1^{\text {neo/neo }}$ mice, which have reduced levels of the NR1 NMDA receptor subunit, show abnormalities in several tests for social behavior, including marked loss of sociability in a choice task $[9,38]$. A similar lack of sociability has recently been reported for mice with decreased NMDA receptor glycine affinity (Grin $1^{\mathrm{D} 481 \mathrm{~N}}$ mice; [30]). The increased sociability found in the present studies is in line with an opposing effect of decreased, versus increased, NRG1 activity on behavior mediated by NMDA receptors. Thus, if increased NRG1-ERBB signaling leads to reduced NMDA receptor 


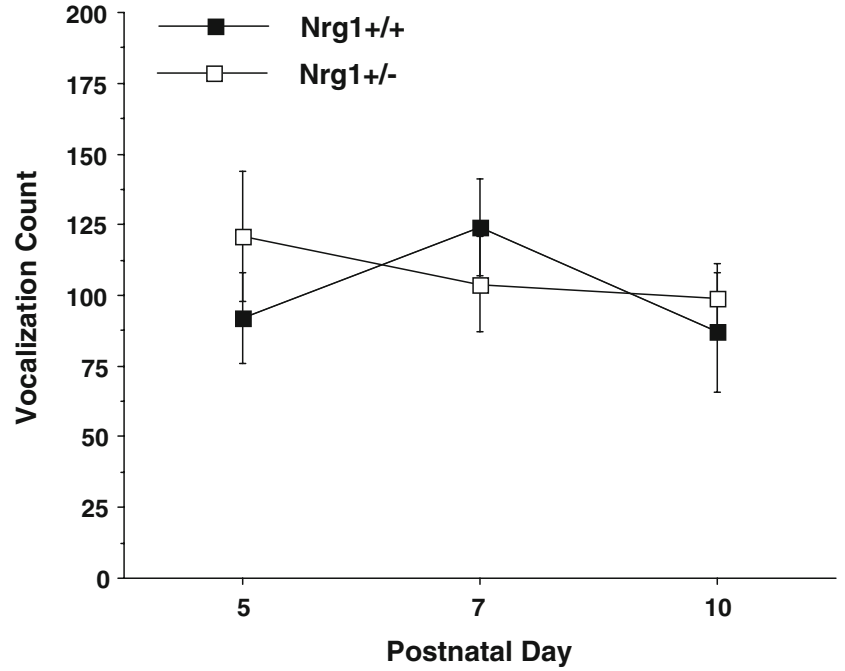

Fig. 5 Frequency of ultrasonic vocalization during social isolation in Nrgl mouse pups. No significant differences were found between the wild-type and heterozygous pups at any age of testing. Mean values for $\mathrm{Nrg} 1+/+$ and $\mathrm{Nrg} 1+/-$ pups within each litter were used for analysis (rather than individual pup scores). Data shown are overall means $( \pm$ SEM $)$ calculated from the litter means $(+/+$ and $+/-)$ for a 5min test. $N=7-10 \mathrm{~L}$ at each time point. Data from one wild-type pup with a very high number of vocalizations $(>500)$ on postnatal day 5 were removed from the analysis

function and deficits in social approach, then disrupted signaling could actually enhance NMDA receptor function, and subsequently increase sociability.

O'Tuathaigh et al. [46] examined performance of $\mathrm{Nrgl} / \mathrm{l}$ mice in the three-chambered choice task. Unlike the present study, the researchers reported no changes in sociability in the mutant mice; both the wild-type and the heterozygous groups had significant preference for the side of the chamber containing the stranger mouse. One reason for the discrepant results could be the background strain used for the mutant mice. O'Tuathaigh et al. [46] tested Nrgl+/- mice on a C57BL/6 background. Inbred strain distributions for social preference have shown that the $\mathrm{C} 57 \mathrm{BL} / 6 \mathrm{~J}$ inbred strain has significant sociability in the choice task [41, 42]. The high levels of sociability in the wild-type groups of the O'Tuathaigh et al. [46] report may have made detection of further increases in the $\mathrm{Nrgl+} /-$ mice difficult. In contrast, three of the wild-type groups in the present study did not show preference for spending more time in proximity to the stranger mouse than to the empty wire cage. It is notable that several inbred mouse strains are characterized by a similar low sociability in the choice task $[41,42]$.

We found a lack of social novelty preference in both $\mathrm{Nrg} 1+/-$ cohort groups, and in the Erbb3 and Erbb4 conditional null mice. O'Tuathaigh et al. [46] reported a similar failure to prefer the newly-introduced stranger 2 mouse to the already-investigated stranger 1 in $\mathrm{Nrgl+l}$ mice (both male and female). Since social novelty preference is dependent upon the ability of the subject mouse to discriminate between the two social partners, one explanation for the findings is that disruption of NRG1ERBB signaling leads to specific deficits in social recognition. In our study and the O'Tuathaigh [46] study, $\mathrm{Nrgl+/-}$ mice were not impaired in a buried food test for olfactory ability, indicating that anosmia in the mutants was not the underlying reason for the lack of social novelty preference. Interestingly, Grin $1^{\mathrm{D} 481 \mathrm{~N}}$ mice had persistent deficits in sociability in the three-chambered choice task, but highly significant preference for stranger 2 , providing evidence that reduced NMDAR function does not disrupt social novelty preference [30]. Preliminary evidence from our laboratory suggests that mice with interneuron-specific deletion of Erbb4 in CNS (Erbb4 $\left.{ }^{l o x /} D l x-C r e\right)$ also have deficient preference for social novelty.

Hyperactivity in various experimental settings has been reported for several $\mathrm{Nrg} 1+/-$ mouse lines [4, 14, 46, 47, 57]. One interpretation for these findings is that disruption of NRG1-ERBB signaling leads to behavioral disinhibition. Thus, increased sociability may be one facet of a general tendency for impulsive behavior in novel environments. However, the $\mathrm{Nrgl}+/-$ mice in the present study did not have higher levels of exploration or activity in either the elevated plus maze or open field tests, indicating that the increased sociability may reflect selective, inappropriate social approach. It is notable that the mutant $\mathrm{Nrgl}$ and Erbb4 lines characterized by hyperactivity were either on a C57BL/6 [4, 46, 47, 57] or a C57BL/6 × 127/SVEV [14] background. Differential effects of targeted gene disruption, dependent upon background strain, have been reported for other mouse models of neuropsychiatric disorders $[8,20,40]$.

In addition to regulation of NMDA receptor function, NRG1 has effects on multiple other neurotransmitter systems [29, 34, 48, 52]. A recent study found that Nrgl+/- mice have general increases of the serotonin transporter in forebrain [7]. We have found that mutant mice with targeted deletion of Slc6a4, the serotonin transporter gene, have a lack of sociability and intact preference for social novelty [40]. Other researchers have reported that Slc6a4-null mice have significant decreases in social interaction and aggression, and are hypoactive across various experimental settings $[21,25,26]$. These findings suggest that the pattern of change observed in the $\mathrm{Nrgl+} /-$ mice is in line with opposing behavioral effects of increased, versus decreased, function of the serotonin transporter, as well as NMDAR function.

Overall, our results provide confirmation that NRG1ERBB signaling plays a significant role in social behavior, which could have implications for neurodevelopmental disorders characterized by social deficits, including schizophrenia, autism, fragile $\mathrm{X}$ syndrome, and Smith-LemliOpitz syndrome. The increased sociability observed in the 
present study may reflect dysregulation of NRG1-mediated NMDAR activity. Functional characterization of $\mathrm{Nrgl}$ overexpressing mice could provide additional evidence of alterations in social approach, as well as other behavioral domains relevant to schizophrenia, mediated by NRG1ERBB signaling.

Acknowledgements The authors would like to thank Dr. Ralf S. Schmid for his assistance with the $\mathrm{Nrg} 1$ mice. This research was supported by National Institutes for Mental Health Silvio O. Conte Center for Neuroscience of Mental Disorders grant P50 MH064065 (Project 5) to E.A., National Alliance for Research on Schizophrenia and Depression (Staglin Music Festival NARSAD Award) to E.A., National Cancer Institute grant CA092479 to D.T., National Science Foundation grant MCB-9729645 to D.T., and National Institute of Child Health and Human Development grant P30 HD03110 to Dr. Joseph Piven.

\section{References}

1. Anton ES, Ghashghaei HT, Weber JL, McCann C, Fischer TM, Cheung ID, et al. Receptor tyrosine kinase ErbB4 modulates neuroblast migration and placement in the adult forebrain. Nat Neurosci. 2004;7:1319-28.

2. Anton ES, Marchionni MA, Lee KF, Rakic P. Role of GGF/ neuregulin signaling in interactions between migrating neurons and radial glia in the developing cerebral cortex. Development. 1997;124:3501-10.

3. Becker A, Grecksch G. Ketamine-induced changes in rat behaviour: a possible animal model of schizophrenia. Test of predictive validity. Prog Neuropsychopharmacol Biol Psychiatry. 2004;28:1267-77.

4. Boucher AA, Arnold JC, Duffy L, Schofield PR, Micheau J, Karl T. Heterozygous neuregulin 1 mice are more sensitive to the behavioural effects of Delta9-tetrahydrocannabinol. Psychopharmacology (Berl). 2007;192:325-36.

5. Buonanno A, Fischbach GD. Neuregulin and ErbB receptor signaling pathways in the nervous system. Curr Opin Neurobiol. 2001;11:287-96.

6. Coyle JT. Glutamate and schizophrenia: beyond the dopamine hypothesis. Cell Mol Neurobiol. 2006;26:365-84.

7. Dean B, Karl T, Pavey G, Boer S, Duffy L, Scarr E. Increased levels of serotonin $2 \mathrm{~A}$ receptors and serotonin transporter in the CNS of neuregulin 1 hypomorphic/mutant mice. Schizophr Res. 2008;99:341-9.

8. Dobkin C, Rabe A, Dumas R, El Idrissi A, Haubenstock H, Brown WT. Fmr1 knockout mouse has a distinctive strain-specific learning impairment. Neuroscience. 2000;100:423-9.

9. Duncan GE, Moy SS, Perez A, Eddy DM, Zinzow WM, Lieberman JA, et al. Deficits in sensorimotor gating and tests of social behavior in a genetic model of reduced NMDA receptor function. Behav Brain Res. 2004;153:507-19.

10. Ellenbroek BA, Cools AR. Animal models for the negative symptoms of schizophrenia. Behav Pharmacol. 2000;11:223-33.

11. Engel AK, Singer W. Temporal binding and the neural correlates of sensory awareness. Trends Cogn Sci. 2001;5:16-25.

12. Fisahn A, Neddens J, Yan L, Buonanno A. Neuregulin-1 modulates Hippocampal gamma oscillations: implications for schizophrenia. Cereb Cortex. 2009;19:612-8.

13. Flames N, Marin O. Developmental mechanisms underlying the generation of cortical interneuron diversity. Neuron. 2005;46:377-81.
14. Gerlai R, Pisacane P, Erickson S. Heregulin, but not ErbB2 or ErbB3, heterozygous mutant mice exhibit hyperactivity in multiple behavioral tasks. Behav Brain Res. 2000;109:219-27.

15. Ghashghaei HT, Weber J, Pevny L, Schmid R, Schwab MH, Lloyd KC, et al. The role of neuregulin-ErbB4 interactions on the proliferation and organization of cells in the subventricular zone. Proc Natl Acad Sci U S A. 2006;103:1930-5.

16. Gu Z, Jiang Q, Fu AK, Ip NY, Yan Z. Regulation of NMDA receptors by neuregulin signaling in prefrontal cortex. J Neurosci. 2005;25:4974-84.

17. Hahn CG, Wang HY, Cho DS, Talbot K, Gur RE, Berrettini WH, et al. Altered neuregulin 1-erbB4 signaling contributes to NMDA receptor hypofunction in schizophrenia. Nat Med. 2006;12:824-8.

18. Harrison PJ, Law AJ. Neuregulin 1 and schizophrenia: genetics, gene expression, and neurobiology. Biol Psychiatry. 2006;60:13240.

19. Hashimoto R, Straub RE, Weickert CS, Hyde TM, Kleinman JE, Weinberger DR. Expression analysis of neuregulin-1 in the dorsolateral prefrontal cortex in schizophrenia. Mol Psychiatry. 2004;9:299-307.

20. Holmes A, Lit Q, Murphy DL, Gold E, Crawley JN. Abnormal anxiety-related behavior in serotonin transporter null mutant mice: the influence of genetic background. Genes Brain Behav. 2003;2:365-80.

21. Holmes A, Murphy DL, Crawley JN. Reduced aggression in mice lacking the serotonin transporter. Psychopharmacology (Berl). 2002;161:160-7.

22. Huang YZ, Won S, Ali DW, Wang Q, Tanowitz M, Du QS, et al. Regulation of neuregulin signaling by PSD-95 interacting with ErbB4 at CNS synapses. Neuron. 2000;26:443-55.

23. Jentsch JD, Roth RH. The neuropsychopharmacology of phencyclidine: from NMDA receptor hypofunction to the dopamine hypothesis of schizophrenia. Neuropsychopharmacology. 1999;20:201-25.

24. Kalkman HO. Altered growth factor signaling pathways as the basis of aberrant stem cell maturation in schizophrenia. Pharmacol Ther. 2009;121:115-22.

25. Kalueff AV, Fox MA, Gallagher PS, Murphy DL. Hypolocomotion, anxiety and serotonin syndrome-like behavior contribute to the complex phenotype of serotonin transporter knockout mice. Genes Brain Behav. 2007;6:389-400.

26. Kalueff AV, Gallagher PS, Murphy DL. Are serotonin transporter knockout mice 'depressed'?: hypoactivity but no anhedonia. Neuroreport. 2006;17:1347-51.

27. Kim JS, Kornhuber HH, Schmid-Burgk W, Holzmuller B. Low cerebrospinal fluid glutamate in schizophrenic patients and a new hypothesis on schizophrenia. Neurosci Lett. 1980;20:379-82.

28. Kwon OB, Longart M, Vullhorst D, Hoffman DA, Buonanno A. Neuregulin-1 reverses long-term potentiation at CA1 hippocampal synapses. J Neurosci. 2005;25:9378-83.

29. Kwon OB, Paredes D, Gonzalez CM, Neddens J, Hernandez L, Vullhorst D, et al. Neuregulin-1 regulates LTP at CA1 hippocampal synapses through activation of dopamine D4 receptors. Proc Natl Acad Sci U S A. 2008;105:15587-92.

30. Labrie V, Lipina T, Roder JC. Mice with reduced NMDA receptor glycine affinity model some of the negative and cognitive symptoms of schizophrenia. Psychopharmacology (Berl). 2008;200:217-30.

31. Law AJ, Lipska BK, Weickert CS, Hyde TM, Straub RE, Hashimoto R, et al. Neuregulin 1 transcripts are differentially expressed in schizophrenia and regulated by 5' SNPs associated with the disease. Proc Natl Acad Sci U S A. 2006;103:6747-52.

32. Li B, Woo RS, Mei L, Malinow R. The neuregulin-1 receptor erbB4 controls glutamatergic synapse maturation and plasticity. Neuron. 2007;54:583-97. 
33. Li D, Collier DA, He L. Meta-analysis shows strong positive association of the neuregulin 1 (NRG1) gene with schizophrenia. Hum Mol Genet. 2006;15:1995-2002.

34. Liu Y, Ford B, Mann MA, Fischbach GD. Neuregulins increase alpha7 nicotinic acetylcholine receptors and enhance excitatory synaptic transmission in GABAergic interneurons of the hippocampus. J Neurosci. 2001;21:5660-9.

35. Lopez-Bendito G, Cautinat A, Sanchez JA, Bielle F, Flames N, Garratt AN, et al. Tangential neuronal migration controls axon guidance: a role for neuregulin-1 in thalamocortical axon navigation. Cell. 2006;125:127-42.

36. Meyer D, Birchmeier C. Multiple essential functions of neuregulin in development. Nature. 1995;378:386-90.

37. Moghaddam B. Recent basic findings in support of excitatory amino acid hypotheses of schizophrenia. Prog Neuropsychopharmacol Biol Psychiatry. 1994;18:859-70.

38. Mohn AR, Gainetdinov RR, Caron MG, Koller BH. Mice with reduced NMDA receptor expression display behaviors related to schizophrenia. Cell. 1999;98:427-36.

39. Moy SS, Nadler JJ, Perez A, Barbaro RP, Johns JM, Magnuson $\mathrm{TR}$, et al. Sociability and preference for social novelty in five inbred strains: an approach to assess autistic-like behavior in mice. Genes Brain Behav. 2004;3:287-302.

40. Moy SS, Nadler JJ, Young NB, Nonneman RJ, Grossman AW, Murphy DL, et al. Social approach in genetically-engineered mouse lines relevant to autism. Genes Brain Behav. 2009;8:129-42.

41. Moy SS, Nadler JJ, Young NB, Nonneman RJ, Segall SK, Andrade GM, et al. Social approach and repetitive behavior in eleven inbred mouse strains. Behav Brain Res. 2008;191:118-29.

42. Moy SS, Nadler JJ, Young NB, Perez A, Holloway LP, Barbaro RP, et al. Mouse behavioral tasks relevant to autism: phenotypes of 10 inbred strains. Behav Brain Res. 2007;176:4-20.

43. Munafo MR, Thiselton DL, Clark TG, Flint J. Association of the NRG1 gene and schizophrenia: a meta-analysis. Mol Psychiatry. 2006;11:539-46.

44. Nadler JJ, Moy SS, Dold G, Trang D, Simmons N, Perez A, et al. Automated apparatus for quantitation of social approach behaviors in mice. Genes Brain Behav. 2004;3:303-14.

45. Norton N, Moskvina V, Morris DW, Bray NJ, Zammit S, Williams $\mathrm{NM}$, et al. Evidence that interaction between neuregulin 1 and its receptor erbB4 increases susceptibility to schizophrenia. Am J Med Genet B Neuropsychiatr Genet. 2006;141B:96-101.

46. O'Tuathaigh CM, Babovic D, O'Sullivan GJ, Clifford JJ, Tighe O, Croke DT, et al. Phenotypic characterization of spatial cognition and social behavior in mice with 'knockout' of the schizophrenia risk gene neuregulin 1. Neuroscience. 2007;147:18-27.
47. O’Tuathaigh CM, O'Connor AM, O’Sullivan GJ, Lai D, Harvey $\mathrm{R}$, Croke DT, et al. Disruption to social dyadic interactions but not emotional/anxiety-related behaviour in mice with heterozygous 'knockout' of the schizophrenia risk gene neuregulin-1. Prog Neuropsychopharmacol Biol Psychiatry. 2008;32:462-6.

48. Okada M, Corfas G. Neuregulin1 downregulates postsynaptic GABAA receptors at the hippocampal inhibitory synapse. Hippocampus. 2004;14:337-44.

49. Olney JW, Farber NB. Glutamate receptor dysfunction and schizophrenia. Arch Gen Psychiatry. 1995;52:998-1007.

50. Rimer M, Barrett DW, Maldonado MA, Vock VM, GonzalezLima F. Neuregulin-1 immunoglobulin-like domain mutant mice: clozapine sensitivity and impaired latent inhibition. Neuroreport. 2005;16:271-5.

51. Rio C, Rieff HI, Qi P, Khurana TS, Corfas G. Neuregulin and erbB receptors play a critical role in neuronal migration. Neuron. 1997;19:39-50.

52. Roy K, Murtie JC, El-Khodor BF, Edgar N, Sardi SP, Hooks BM, et al. Loss of erbB signaling in oligodendrocytes alters myelin and dopaminergic function, a potential mechanism for neuropsychiatric disorders. Proc Natl Acad Sci U S A. 2007;104:8131-6.

53. Rung JP, Carlsson A, Ryden Markinhuhta K, Carlsson ML. (+)MK-801 induced social withdrawal in rats; a model for negative symptoms of schizophrenia. Prog Neuropsychopharmacol Biol Psychiatry. 2005;29:827-32.

54. Sams-Dodd F. Phencyclidine in the social interaction test: an animal model of schizophrenia with face and predictive validity. Rev Neurosci. 1999;10:59-90.

55. Schmid RS, McGrath B, Berechid BE, Boyles B, Marchionni M, Sestan N, et al. Neuregulin 1-erbB2 signaling is required for the establishment of radial glia and their transformation into astrocytes in cerebral cortex. Proc Natl Acad Sci U S A. 2003;100:4251-6.

56. Stefansson H, Sarginson J, Kong A, Yates P, Steinthorsdottir V, Gudfinnsson E, et al. Association of neuregulin 1 with schizophrenia confirmed in a Scottish population. Am J Hum Genet. 2003;72:83-7.

57. Stefansson H, Sigurdsson E, Steinthorsdottir V, Bjornsdottir S, Sigmundsson T, Ghosh S, et al. Neuregulin 1 and susceptibility to schizophrenia. Am J Hum Genet. 2002;71:877-92.

58. Williams NM, Preece A, Spurlock G, Norton N, Williams HJ, Zammit $\mathrm{S}$, et al. Support for genetic variation in neuregulin 1 and susceptibility to schizophrenia. Mol Psychiatry. 2003;8:485-7.

59. Woo RS, Li XM, Tao Y, Carpenter-Hyland E, Huang YZ, Weber $\mathrm{J}$, et al. Neuregulin-1 enhances depolarization-induced GABA release. Neuron. 2007;54:599-610. 